Article

\title{
Fate of Fertilizer-Derived N Applied to Enhance Rice Straw Decomposition in a Paddy Field during the Fallow Season under Cool Temperature Conditions
}

\author{
Fumiaki Takakai ${ }^{1, *(D)}$, Seiya Hirano ${ }^{1}$, Yuka Harakawa ${ }^{2}$, Keiko Hatakeyama ${ }^{1}$, \\ Kentaro Yasuda ${ }^{1}$ (D), Takashi Sato ${ }^{1}$, Kazuhiko Kimura ${ }^{2}$ and Yoshihiro Kaneta ${ }^{1}$ \\ 1 Faculty of Bioresource Sciences, Akita Prefectural University, 241-438 Aza Kaidobata-Nishi, \\ Shimoshinjo Nakano, Akita 010-0195, Japan; sgws.ma@gmail.com (S.H.); \\ k_hatakeyama@akita-pu.ac.jp (K.H.); kentaroy@akita-pu.ac.jp (K.Y.); t_sato@akita-pu.ac.jp (T.S.); \\ ykaneta@akita-pu.ac.jp (Y.K.) \\ 2 School of Food, Agricultural and Environmental Sciences, Miyagi University, 2-2-1 Hatadate, Taihaku-ku, \\ Sendai 982-0215, Japan; you.can.6920@gmail.com (Y.H.); kimurakz@myu.ac.jp (K.K.) \\ * Correspondence: takakai@akita-pu.ac.jp or ftakakai@gmail.com; Tel.: +81-18-872-1612; Fax: +81-18-872-1677
}

Received: 8 February 2018; Accepted: 29 March 2018; Published: 30 March 2018

\begin{abstract}
A field experiment was conducted to evaluate the fate of nitrogen $(\mathrm{N})$ derived from fertilizer (fertilizer-derived $\mathrm{N}$ ) applied to a paddy field after rice harvesting to promote rice straw decomposition during the fallow season, and to determine its effect on soil $\mathrm{N}$ fertility in northern Japan. A frame containing soil mixed with rice straw and ${ }^{15} \mathrm{~N}$-labeled fertilizer $\left(4.3 \mathrm{~g} \mathrm{~N} \mathrm{~m}^{-2}\right.$ ammonium sulfate [AS] or lime-nitrogen [LN]) was placed into a paddy field on a gray lowland soil during the fallow season (October-April), and the following rice-growing season (May-September). Before cultivation (April), the percentages of fertilizer-derived $\mathrm{N}$ in soil + straw were higher for LN (55-72\%) than for AS (41-63\%). At the harvesting stage (September), the percentages of fertilizer-derived $\mathrm{N}$ in plants were significantly higher for LN (4.9-6.2\%) than for AS (3.4-5.3\%), and the percentages in soil were also significantly higher for LN (42-61\%) than for AS (31-38\%). This could be attributed to the nitrification inhibitory effect of $\mathrm{LN}$ and result in the suppression of $\mathrm{N}$ losses via leaching. Consequently, fertilizer-derived $\mathrm{N}$ could contribute to the maintenance of soil $\mathrm{N}$ fertility, and this effect could be higher for LN than AS.
\end{abstract}

Keywords: ammonium sulfate; ${ }^{15} \mathrm{~N}$; paddy soil; rice growth; rice straw decomposition

\section{Introduction}

Rice straw is scattered over the paddy field after combine harvesting and remains throughout the following fallow season, including over the winter for much current rice cultivation in Japan. Insufficient decomposition of rice straw due to the cold climate could lead to several problems for rice cultivation during the following year in cool-temperate regions, such as northern Japan. The initial rice growth is suppressed by the extreme reduction of saturated soil and the production of organic acids after flooding and in the presence of nitrogen $(\mathrm{N})$ deficiency, for example. Therefore, the enhancement of microbial rice straw decomposition during the fallow season, such as the incorporation of rice straw into the soil after applying $\mathrm{N}$ fertilizers, is important in this region $[1,2]$.

Lime-nitrogen (LN) has been used widely for over 100 years as a fertilizer, pesticide and soil amendment in agricultural production [3]. Lime-nitrogen is produced from the reaction of calcium carbide $\left(\mathrm{CaC}_{2}\right)$ with di-nitrogen $\left(\mathrm{N}_{2}\right)$ at high temperature (approximately $1200{ }^{\circ} \mathrm{C}$ ) and contains approximately $55 \%$ calcium cyanamide $\left(\mathrm{CaCN}_{2}\right)$ as the principal component. Calcium cyanamide is hydrolyzed to cyanamide $\left(\mathrm{H}_{2} \mathrm{CN}_{2}\right)$ after soil application. During decomposition, the cyanamide is converted to urea, and a portion 
of cyanamide is converted into dicyandiamide (DCD), a nitrification inhibitor. Additionally, the cyanamide itself functions as a nitrification inhibitor [4]. Therefore, $\mathrm{N}$ derived from $\mathrm{LN}$ remains in the soil longer than that derived from the popular chemical fertilizer ammonium sulfate [5,6]. The Ministry of Agriculture, Forestry and Fisheries of Japan authorized LN as a type of controlled-release fertilizer in 2013. Recently, the reduction of nitrous oxide emissions from the uplands and tea fields via the application of LN have frequently been verified, highlighting the nitrification inhibitory effect of this compound [6-9].

Lime-nitrogen is an effective fertilizer that enhances rice straw decomposition, and improved growth and yield of rice has been widely reported, particularly in northern Japan $[1,10]$. The enhancement of organic matter decomposition via the effect of alkalinity, as well as the lowering of the $\mathrm{C} / \mathrm{N}$ ratio of the rice straw, has been implicated as the mechanism of enhanced rice straw decomposition due to LN application [3]. The conventional usage of LN to enhance rice straw decomposition involves the application of $10-20 \mathrm{~g} \mathrm{~m}^{-2} \mathrm{LN}\left(2-4 \mathrm{~g} \mathrm{~N} \mathrm{~m}^{-2}\right)$ to the rice straw after the harvest for incorporation into the soil. A portion of the $\mathrm{N}$ derived from the applied $\mathrm{LN}$ is thought to remain in the soil and the rice straw and could be taken up by the rice plants cultivated in the following year. Thus, the application of LN could enhance rice growth, not only by enhancing rice straw decomposition but also by increasing the $\mathrm{N}$ supply. Therefore, a quantitative evaluation of the fate of $\mathrm{N}$ (taken up by the rice plants and remaining in the soil) derived from LN applied as a fertilizer is necessary. Moreover, the plant and soil $\mathrm{N}$ derived from $\mathrm{LN}$ is considered to be higher than those from ammonium sulfate (AS) due to its nitrification inhibitory effect. However, a few studies concerning the fate of $\mathrm{N}$ under field conditions have been done, particularly to gain information on the $\mathrm{N}$ remaining in the soil. Additionally, the progress of rice straw decomposition by incorporation in autumn could vary greatly depending on the soil and climate conditions, such as temperature and precipitation [1]. Because the transformation of $\mathrm{N}$ in soil also could vary greatly depending on the soil and climate conditions, the fate of $\mathrm{N}$ derived from fertilizer for enhancing rice straw decomposition might be influenced by differences in these conditions.

The present study employed ${ }^{15} \mathrm{~N}$ tracer experiments using AS as a reference in two paddy fields at different locations in a cool-temperate climate. The purpose is to evaluate the fate of $\mathrm{N}$ derived from LN applied as a fertilizer to enhance rice straw decomposition and determine its effect on soil $\mathrm{N}$ fertility.

\section{Materials and Methods}

\subsection{Experimental Setup and Cultivation}

This study quantitatively evaluated the fate of fertilizer $\mathrm{N}$ applied in autumn to enhance rice straw decomposition via a field experiment using a frame with an ${ }^{15} \mathrm{~N}$ tracer according to the methods of Nishida et al. [11]. The winter climate of Tohoku region, northern Japan, is divided roughly into the Japan Sea side with higher precipitation (mainly snow) and Pacific side with low precipitation. To cover both climate condition, this study was conducted in Akita and Miyagi prefectures, located on the Japan Sea side and Pacific side of Tohoku region, respectively.

The field experiment was conducted at a continuous rice paddy field in the Field Education and Research Center of Akita Prefectural University in the Akita Prefecture (Akita, $40^{\circ} 00^{\prime} \mathrm{N}, 139^{\circ} 57^{\prime} \mathrm{E}$ ), and on the Taihaku Campus of Miyagi University, in the Miyagi Prefecture (Miyagi, $38^{\circ} 14^{\prime} \mathrm{N}, 139^{\circ} 49^{\prime} \mathrm{E}$ ) for one year (October 2013-September 2014). Both sites were in Tohoku region, northern Japan.

The soil temperature was higher than $10{ }^{\circ} \mathrm{C}$ from the beginning of the experiment from the middle of October to early November and subsequently declined and remained near $0^{\circ} \mathrm{C}$ during the snowy season (Figure 1) at both sites. The cumulative soil temperature from the middle of October (the start of the experiment) to the end of November, which is thought to be the period when the rapid decomposition of rice straw occurs, was higher in Miyagi $\left(449^{\circ} \mathrm{C} \cdot \mathrm{d}\right)$ than in Akita $\left(373^{\circ} \mathrm{C} \cdot \mathrm{d}\right.$ : degree Celsius day). Similarly, the cumulative soil temperature during the entire fallow season that ran 
from the start of the experiment to sampling before cultivation in early April (for more detailed dates, see Table 1) was higher in Miyagi $\left(779^{\circ} \mathrm{C} \cdot \mathrm{d}\right)$ than in Akita $\left(598^{\circ} \mathrm{C} \cdot \mathrm{d}\right)$. The cumulative soil temperature during the entire experimental period in Miyagi $\left(3985^{\circ} \mathrm{C} \cdot \mathrm{d}\right.$ ) was slightly higher than that in Akita $\left(3773^{\circ} \mathrm{C} \cdot \mathrm{d}\right)$, and this difference was primarily observed in the fallow season. The total precipitation from the middle of October to the end of November was higher in Akita (302 mm) than in Miyagi $(169 \mathrm{~mm})$. A similar tendency was also observed for the entire fallow season (789 and $548 \mathrm{~mm}$ for Akita and Miyagi, respectively).
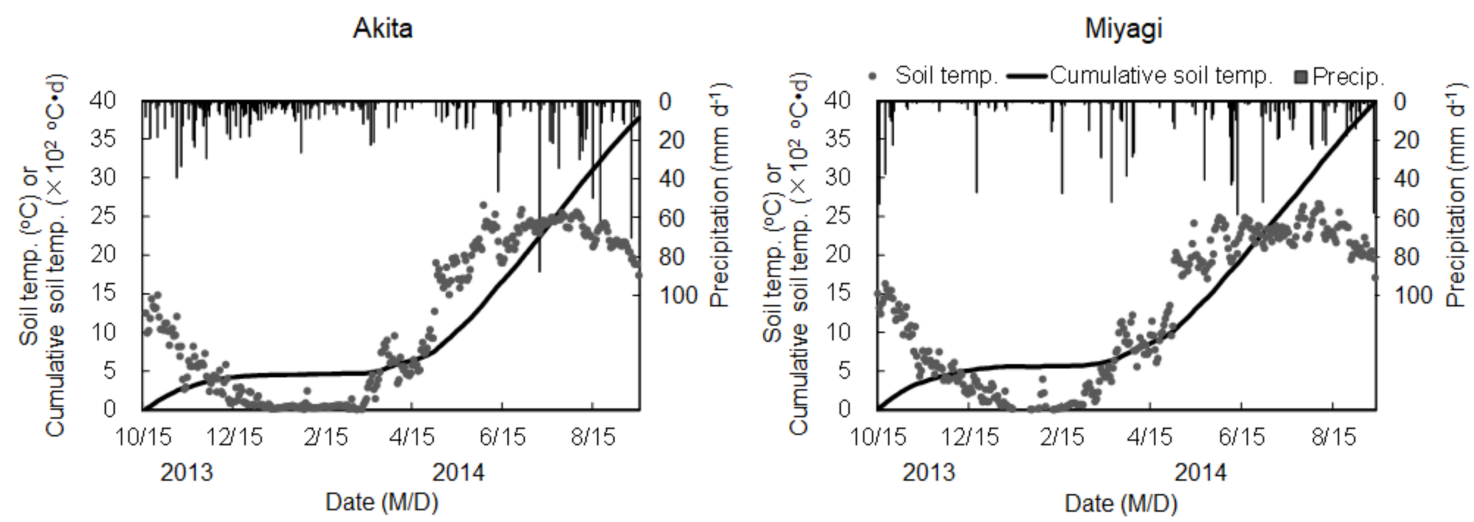

Figure 1. Seasonal changes in the daily (plot) and cumulative soil temperature (line) and precipitation (bar, ${ }^{\circ} \mathrm{C} \cdot \mathrm{d}$ : degree Celsius day). The precipitation data were obtained using an automated meteorological data acquisition system (AMeDAS) near each experimental field. The soil temperature was measured at a depth of $5 \mathrm{~cm}$ and $7.5 \mathrm{~cm}$ (center of $15 \mathrm{~cm}$ corresponding to plowed layer) from the soil surface inside the plot using a temperature logger (Ondotori TR-71U, T\&D Corporation, Matsumoto, Japan) during the fallow and growing season, respectively. The soil temperature was measured with four replications, regardless of the $\mathrm{N}$-fertilizer type at both sites.

Table 1. Dates of cultivation management, investigation and sampling.

\begin{tabular}{ccc}
\hline Practice & Date & Miyagi \\
\cline { 2 - 3 } Soil collection & Akita & 7 October 2013 \\
\hline Frame install (fallow) & 30 September 2013 & 15 October 2013 \\
\hline $\begin{array}{c}\text { Frame collection and sampling (soil and rice } \\
\text { straw, before cultivation) }\end{array}$ & 17 October 2013 2014 \\
\hline Frame install (paddy) and transplanting & 7 April 2014 & 15 May 2014 \\
\hline Plant growth investigation (tillering stage) & 28 May 2014 June 2014 (39) \\
\hline $\begin{array}{c}\text { Plant growth investigation (maximum tiller } \\
\text { number stage) }\end{array}$ & 25 June 2014 (28) & 7 July 2014 (53) \\
\hline $\begin{array}{c}\text { Plant growth investigation and sampling (plant, } \\
\text { panicle initiation stage) }\end{array}$ & 14 July 2014 (47) & 14 July 2014 (60) \\
\hline Mid-season drainage & - & Late June 2014 (one week) \\
\hline Start of intermittent irrigation & 12 August 2014 (76) & End of July 2014 \\
\hline Plant growth investigation(full heading stage) & Early September 2014 & 13 August 2014 (90) \\
\hline Final drainage & 15 September 2014 (110) & 12 September 2014 (120)
\end{tabular}

A polyvinyl chloride frame $(17 \times 30 \times 25 \mathrm{~cm}$, length $\times$ width $\times$ height, corresponding to the area of one rice hill) wrapped at the bottom with unwoven cloth which allows water to pass downward was prepared in October 2013. The frame was filled with a mixture of fresh soil (6.0 kg on a dry soil basis), rice straw and ${ }^{15} \mathrm{~N}$-labeled $\mathrm{N}$ fertilizer (AS or LN) to a depth of $15 \mathrm{~cm}$, and the frame was subsequently installed into the plowed layer $(15 \mathrm{~cm}$ depth) in a paddy field after the harvest (Table 1). Fresh soil 
collected from the plowed layer of a continuous paddy field at the Agricultural Experimental Station of Akita Prefecture (Akita) and in Taihaku Campus of Miyagi University (Miyagi) after the rice was harvested in October 2013 was used for the present study. The soil type in both fields was classified as a gray lowland soil in the classification of cultivated soils in Japan [12] and Fluvisol in the World Reference Base classification [13]. Prior to the experiment, the collected soil was air-dried for a few days and crushed to pass through a 5-cm sieve, and the rice straw and rice stubble in the soil were subsequently removed manually. The chemical properties of the studied soils are shown in Table 2 . The application rate of ${ }^{15} \mathrm{~N}$-labeled fertilizer (both AS and LN) was determined as $4.3 \mathrm{~g} \mathrm{~N} \mathrm{~m}^{-2}$ based on the recommended application rate $\left(20 \mathrm{~g} \mathrm{~m}^{-2}\right)$ of LN (21.5\% in total N). Granular AS (10.3 atom\%) and LN (10.6 atom\%) were used in the present study.

Assuming a standard grain yield of $600 \mathrm{~g} \mathrm{~m}^{-2}$ and a grain:straw ratio of 1:1, the amount of incorporated rice straw (Oryza sativa L.) was determined as $600 \mathrm{~g} \mathrm{~m}^{-2}$ based on the air-dried weight. The rice straw cultivars used in Akita and Miyagi were Akitakomachi (502 $\mathrm{g} \mathrm{DW} \mathrm{m}^{-2}, \mathrm{C} / \mathrm{N}$ ratio: 59.0) and Hitomebore ( $518 \mathrm{~g} \mathrm{DW} \mathrm{m}^{-2}, \mathrm{C} / \mathrm{N}$ ratio: 44.9 ), respectively. The rice straw was air-dried after the harvest and cut into pieces $5-\mathrm{cm}$ in length for use in subsequent experiments. Assuming that the rice straw was incorporated by shallow plowing, the rice straw and fertilizer were incorporated into the soil to a depth of only $5 \mathrm{~cm}$. Sampling was conducted three times during the experimental period $(n=4$, respectively), and 12 frames were prepared at each site for each fertilizer (subsequently described in detail below). All the frames were installed in line in the field without intervals between the frames.

All the frames installed in the field during the fallow season were temporarily removed from the field before cultivation in the next year (April 2014). Then, four frames for each treatment were used to collect soil and rice straw samples. The other frames were maintained in outdoor spaces under climate conditions similar to those in the field until subsequent re-installation of the frame after transplantation.

The remaining frames were re-installed into the plowed layer of the paddy field after puddling in late May and the rice was cultivated inside the frame. Prior to installation, chemical fertilizer ( $\mathrm{N}$ [non-labeled] $-\mathrm{P}_{2} \mathrm{O}_{5}-\mathrm{K}_{2} \mathrm{O}=14-14-14 \%$ ) was applied as a basal dressing to each plot at a rate of 5-5-5 g m ${ }^{-2}\left(\mathrm{~N}-\mathrm{P}_{2} \mathrm{O}_{5}-\mathrm{K}_{2} \mathrm{O}\right)$ for Akita and 4-4-4 $\mathrm{g} \mathrm{m}^{-2}$ for Miyagi, respectively. The frames were installed in the field in a single row at $68-\mathrm{cm}$ intervals (center to center), including three hills of rice plants between the two frames. Once the frames were installed at a depth of $15 \mathrm{~cm}$ in the field, water was added to the soil in the frame and puddling was conducted. Then, the three 35-day-old rice seedlings (cv. Akitakomachi for Akita and Hitomebore for Miyagi, respectively) were transplanted to the center of each frame.

A few days after transplanting, the puddled soil inside the plot was sufficiently precipitated, and a hole ( $2 \mathrm{~cm}$ in diameter) located slightly higher than ground level was opened on each side of the frame (the holes were previously closed with a rubber stopper) to maintain an unrestricted flow of flooding water into and out of the plot during the growing season.

The rice cultivation management was conducted according to local conventions at each site. The irrigation management is described in Table 1. No fertilizer top-dressing was applied at either site.

\subsection{Investigation of the Growth of Rice Plants}

The plant height, number of tillers and leaf color value were periodically measured during the growing period. These parameters were measured at the tillering, maximum tiller number, panicle initiation and full heading stages (Table 1). The number of tillers at the full heading stage corresponded to the number of panicles. The leaf color value (SPAD value) was measured using a chlorophyll meter (SPAD-502, KONICA MINOLTA, INC., Tokyo, Japan) at the next leaf below the uppermost, unfolded leaf $(n-1)$, except at the full heading stage, when it was measured at the flag leaf. 
Table 2. Chemical properties of the studied soils.

\begin{tabular}{|c|c|c|c|c|c|c|c|c|c|c|c|c|c|}
\hline \multirow{2}{*}{ Site } & \multirow{2}{*}{ Soil Type } & \multirow{2}{*}{$\begin{array}{c}\mathrm{pH} \\
\left(\mathrm{H}_{2} \mathrm{O}\right) \\
\end{array}$} & \multirow{2}{*}{$\begin{array}{c}\mathrm{EC} \\
\left(\mathrm{mS} \mathrm{cm}^{-1}\right)\end{array}$} & \multicolumn{4}{|c|}{ Exchangeable Cations $\left(\mathrm{cmol}_{\mathrm{C}} \mathrm{kg}^{-1}\right.$ ) } & \multirow{2}{*}{$\begin{array}{c}\text { CEC } \\
\left(\mathrm{cmol}_{\mathrm{C}} \mathrm{kg}^{-1}\right) \\
\end{array}$} & \multirow{2}{*}{$\begin{array}{r}\text { Total-C } \\
\left(\mathrm{g} \mathrm{kg}^{-1}\right)\end{array}$} & \multirow{2}{*}{$\begin{array}{c}\text { Total-N } \\
\left(\mathrm{g} \mathrm{kg}^{-1}\right)\end{array}$} & \multirow[t]{2}{*}{ C/N Ratio } & \multirow{2}{*}{$\begin{array}{c}\text { Available }{ }^{\dagger} \\
\left(\mathrm{mg} \mathrm{N} \mathrm{kg}^{-1}\right) \\
\end{array}$} & \multirow{2}{*}{$\begin{array}{c}\text { Available } \mathrm{P}^{\ddagger} \\
\left(\mathrm{mg} \mathrm{P}_{2} \mathrm{O}_{5} \mathrm{~kg}^{-1}\right)\end{array}$} \\
\hline & & & & K & $\mathrm{Na}$ & $\mathrm{Ca}$ & $\mathrm{Mg}$ & & & & & & \\
\hline Akita & Gray lowland soil & 5.75 & 0.07 & 0.27 & 0.24 & 10.8 & 3.00 & 17.4 & 26.7 & 2.37 & 11.3 & 162.0 & 359 \\
\hline Miyagi & Gray lowland soil & 6.50 & 0.15 & 0.80 & 1.09 & 17.3 & 2.62 & 19.3 & 19.3 & 1.80 & 10.7 & 107.0 & 189 \\
\hline
\end{tabular}

${ }^{\dagger} \mathrm{NH}_{4}$ - $\mathrm{N}$ for 4-week incubation of air-dried soil under flooded conditions at $30{ }^{\circ} \mathrm{C} .{ }^{\ddagger}$ Truog-P. EC, electrical conductivity; CEC, cation exchange capacity 


\subsection{Sample Collection and Analysis}

The samples were collected before cultivation (soil and rice straw) and at the panicle initiation (plant) and harvesting (soil and plant) stages of rice with four replications per sampling time (Table 1). Subsequently, the distribution of fertilizer-derived $\mathrm{N}$ was quantitatively evaluated by analysis of the ${ }^{15} \mathrm{~N}$ content.

Before cultivation in early April, rice straw was collected from the soil inside the plot. The rice straw was completely removed from one-quarter of the soil with tweezers. The collected rice straw was carefully wiped to remove the attached soil and subsequently oven-dried at $80^{\circ} \mathrm{C}$. The dry matter weight of the rice straw sample was subsequently measured, and the sample was finely ground using a mixer mill (MM301, Retsch GmbH, Haan, Germany). Once the rice straw was collected, the soil was air-dried and sieved (2-mm mesh). A portion of the air-dried soil sample was subsequently finely ground using an agate mortar and pestle. Another three-quarters of the soil sample was washed to collect rice straw for measurement of the dry matter weight. The dry matter weight of the rice straw in the entire soil sample inside the plot was calculated as the sum of both dry matter weights.

At the panicle initiation stage (middle July), the aboveground plant samples were collected, washed with water, oven-dried at $80{ }^{\circ} \mathrm{C}$ and subsequently weighed. The plant samples were ground using a cutting mill (SM 100, Retsch GmbH) and an ultra-centrifugal mill (ZM 100, Retsch GmbH), and a portion of the ground plant samples was finely ground using a mixer mill.

At the harvesting stage in the middle of September, aboveground plant samples were collected, separated into panicles and stems/leaves, and subsequently treated in the same manner as the plant samples taken at the panicle initiation stage. The soil samples from the plots were air-dried and sieved (2-mm mesh). Coarse organic matter (straw and roots of rice, etc.) was removed by the sieving and oven-dried at $80^{\circ} \mathrm{C}$. Subsequently, the material was finely ground using a mixer mill, and then mixed with the air-dried soil samples. Following mixing, a portion of the air-dried soil samples was finely ground.

The total $\mathrm{N}$ content and ${ }^{15} \mathrm{~N}$ abundance of the finely ground samples were measured using an N/C analyzer (SUMIGRAPH NC-22F; Sumika Chemical Analysis Service, Osaka, Japan) and an elemental analyzer/isotope ratio mass spectrometer (FLASH EA 1112 SERIES and DELTA ${ }^{\text {plus } X P \text {, }}$ Thermo Finnigan MAT, Bremen, Germany), respectively. Regarding the rice straw samples before cultivation, the total carbon (C) content was simultaneously measured to calculate the decomposition rate during the fallow season.

\subsection{Calculation of the Fertilizer-Derived N Distribution}

The amount of soil $\mathrm{N}$ derived from fertilizer was calculated using the following Equation (1):

Soil $\mathrm{N}$ derived from fertilizer $\left(\mathrm{g} \mathrm{N} \mathrm{m}^{-2}\right)=($ AEs $/ \mathrm{AEm}) \times \mathrm{TNs}$

where AEs is the ${ }^{15} \mathrm{~N}$ atom\% excess in soil (atom\%), AEm is the ${ }^{15} \mathrm{~N}$ atom $\%$ excess in fertilizer (atom\%), and TNs is the total soil $\mathrm{N}$ storage $\left(\mathrm{g} \mathrm{N} \mathrm{m}^{-2}\right)$. The value of ${ }^{15} \mathrm{~N}$ atom\% excess was calculated after subtracting the natural ${ }^{15} \mathrm{~N}$ abundance $\left(0.3663\right.$ atom\%) from the ${ }^{15} \mathrm{~N}$ abundance of each sample. The rice straw and plant $\mathrm{N}$ derived from fertilizer were calculated using Equation (1).

During the study period, considerable loss of $\mathrm{N}$ derived from fertilizer applied to the soil inside the frame (i.e., plowed layer) can occur. A portion of $\mathrm{N}$ derived from fertilizer can be transformed into nitrate $\mathrm{N}\left(\mathrm{NO}_{3}-\mathrm{N}\right)$ via ammonium $\mathrm{N}\left(\mathrm{NH}_{4}-\mathrm{N}\right)$ by nitrification. Then, the $\mathrm{NO}_{3}-\mathrm{N}$ can be lost from the soil mainly due to leaching via rainwater percolation downward and $\mathrm{N}_{2}$ emission to the atmosphere via denitrification under anaerobic conditions. The amounts of loss of $\mathrm{N}$ derived from fertilizer before cultivation and at the harvesting stage were calculated using Equations (2) and (3):

Loss of $\mathrm{N}$ derived from fertilizer before cultivation $\left(\mathrm{g} \mathrm{N} \mathrm{m}^{-2}\right)=\mathrm{MNa}-\mathrm{MNrs}-\mathrm{MNs}$ 
Loss of $\mathrm{N}$ derived from fertilizer at the harvesting stage $\left(\mathrm{g} \mathrm{N} \mathrm{m}^{-2}\right)=\mathrm{MNa}-\mathrm{MNp}-\mathrm{MNs}$

where $\mathrm{MNa}$ is the applied fertilizer $\mathrm{N}, \mathrm{MNrs}$ is the rice straw $\mathrm{N}$ derived from fertilizer, MNs is the soil $\mathrm{N}$ derived from fertilizer and $\mathrm{MNp}$ is the plant $\mathrm{N}$ derived from fertilizer (all units are $\mathrm{g} \mathrm{N} \mathrm{m}^{-2}$ ).

The distribution of $\mathrm{N}$ derived from fertilizer was expressed as the percentage of applied $\mathrm{N}(\%)$. The plant uptake of total and fertilizer $\mathrm{N}$ during the later growing period was calculated by subtracting the $\mathrm{N}$ uptake at the panicle initiation stage (the early growing period) from the $\mathrm{N}$ uptake at the harvesting stage.

\subsection{Analysis of Labile Soil N Derived from Fertilizer}

The amount of $\mathrm{N}$ derived from fertilizer in the soil fraction was evaluated for available $\mathrm{N}$ using an incubation method [14] for the soil collected from the plots before cultivation and at the harvesting stage, as described in a previous Section 2.3.

Following a 4-week incubation of the air-dried soil under flooded conditions at $30{ }^{\circ} \mathrm{C}$, the mineralized $\mathrm{N}$ content $\left(\mathrm{NH}_{4}-\mathrm{N}\right.$ ), which is defined as the labile soil $\mathrm{N}$ (available $\mathrm{N}$ ), and the abundance of ${ }^{15} \mathrm{~N}$ in the $\mathrm{N}$ were measured. The soil was extracted with $10 \% \mathrm{KCl}$ after incubation, and the $\mathrm{NH}_{4}-\mathrm{N}$ concentration was subsequently determined using an indophenol blue method. Pretreatment and ${ }^{15} \mathrm{~N}$ analysis of the extracted solution sample were conducted with the diffusion method of Yoneyama et al. [15] and Nishida et al. [11], with minor modifications. Briefly, an extracted solution sample containing approximately $50 \mu \mathrm{g} \mathrm{N}$ was placed in a 50-mL Erlenmeyer flask, $1 \mathrm{~mL}$ of $40 \% \mathrm{NaOH}$ was subsequently added and the flask was immediately sealed. The ammonia $\left(\mathrm{NH}_{3}\right)$ in the flask that was volatilized during a 70-h incubation was trapped using an absorption solution $(250 \mu \mathrm{L}$ of $2 \mathrm{~N} \mathrm{H}_{3} \mathrm{BO}_{3}$ ).

Once the $\mathrm{NH}_{3}$ was trapped, the absorption solution was placed in a tin capsule and freeze-dried for one day, then the ${ }^{15} \mathrm{~N}$ abundance in the sample was analyzed. Three replicates for each sample were tested. Details of the experimental procedure (reagent quantities, reaction time, etc.) were determined based on preliminary experiments with AS. The recovery rate of applied $\mathrm{N}$ via this procedure was $96 \%$.

The amount of labile soil $\mathrm{N}$ derived from fertilizer was calculated using Equation (1), as described in a previous Section 2.4. The amount of recalcitrant soil $\mathrm{N}$ derived from fertilizer was estimated via Equation (4) as the difference between the amount of soil $\mathrm{N}$ and the labile soil $\mathrm{N}$ derived from fertilizer, as calculated in the previous Sections 2.3 and 2.4.

$$
\begin{aligned}
& \text { Recalcitrant soil } \mathrm{N} \text { derived from fertilizer }\left(\mathrm{g} \mathrm{N} \mathrm{m}^{-2}\right) \\
& \quad \text { - Total soil } \mathrm{N} \text { derived from fertilizer }\left(\mathrm{g} \mathrm{N} \mathrm{m}^{-2}\right) \\
& - \text { Labile soil } \mathrm{N} \text { derived from fertilizer }\left(\mathrm{g} \mathrm{N} \mathrm{m}^{-2}\right)
\end{aligned}
$$

\subsection{Statistical Analysis}

Differences in rice straw decomposition and distribution of $\mathrm{N}$ derived from fertilizer between the fertilizers and sites were compared using two-way analysis of variance (ANOVA). Since the growth pattern of rice cultivar used in each site were different, the growth, dry matter and $\mathrm{N}$ uptake of rice plants between the fertilizers were compared at each site using the $t$-test. Excel Statistics 2012 (SSRI, Tokyo, Japan) was used for all the statistical analyses.

\section{Results}

\subsection{Rice Straw Decomposition during the Fallow Sseason}

The decomposition rate ( $\mathrm{C}$ loss basis) and the $\mathrm{C} / \mathrm{N}$ ratio of the rice straw before cultivation are shown in Figure 2. The decomposition rate did not differ significantly with fertilizer and site (49 and $52 \%$ for AS and LN in Akita, 50 and 57\% for AS and LN in Miyagi, respectively). The C/N ratio of rice straw did not differ significantly with fertilizer, and was significantly higher in Akita (23 and 24 for AS and LN, respectively) than in Miyagi (30 and 27 for AS and LN, respectively). 
[ Two-way ANOVA ]

\begin{tabular}{lcc}
\multicolumn{1}{c}{ Factor } & Decomposition rate & $\mathrm{C} / \mathrm{N}$ ratio \\
\hline Fertilizer & $\mathrm{ns}$ & $\mathrm{ns}$ \\
Site & $\mathrm{ns}$ & $* * *$ \\
$\mathrm{~F} \times \mathrm{S}$ & $\mathrm{ns}$ & $\mathrm{ns}$ \\
\hline $\mathrm{ns}$ for $P>0.05 ; * *$ for $P<0.01$. &
\end{tabular}

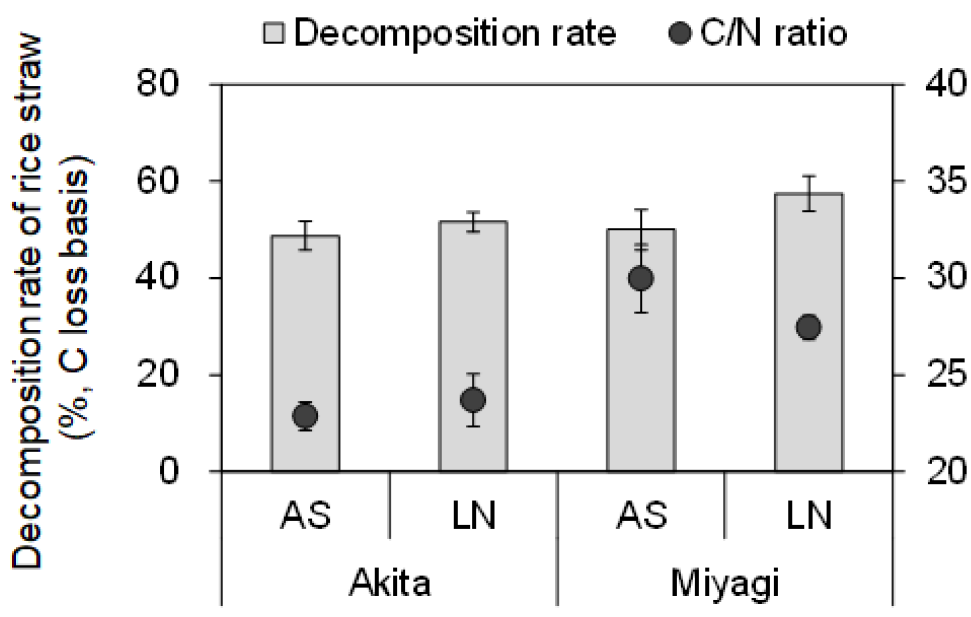

Figure 2. Decomposition rate (C loss basis) and $\mathrm{C} / \mathrm{N}$ ratio of rice straw before cultivation. $\mathrm{AS}$, ammonium sulfate; LN, lime nitrogen. The error bars show the standard error $(n=4)$.

\subsection{Dynamics of Fertilizer-Derived $N$ during the Fallow Season}

The distribution of fertilizer-derived $\mathrm{N}$ before cultivation is shown in Figure 3 and Table S1. The percentages of soil $\mathrm{N}$ derived from LN (43-62\%) were higher than those from AS (32-58\%), although the difference was not significant $(p=0.059)$. The percentages of labile soil $\mathrm{N}$ derived from LN (9.9-18.3\%) were higher than those from AS (8.5-18.0\%), although the difference was not significant. The percentages of recalcitrant soil N derived from LN (33-49\%) were significantly higher than those from AS (24-40\%) The proportion of labile soil $\mathrm{N}$ derived from fertilizer to total fertilizer-derived $\mathrm{N}$ in the soil were similar between AS (26-31\%) and LN (23-27\%). The percentages of fertilizer-derived N in the soil (32-62\%) were higher than in rice straw (4.9-11.6\%), suggesting that the fertilizer-derived $\mathrm{N}$ primarily remained in the soil. The percentages of $\mathrm{N}$ derived from LN in the soil and the rice straw (rice straw + soil) were significantly higher than those from AS. The percentages of $\mathrm{N}$ in soil (including labile and recalcitrant) and rice straw + soil derived from fertilizer in Miyagi were significantly higher than those in Akita. Losses of $\mathrm{N}$ derived from fertilizer ranged from 28 to $59 \%$, and were significantly higher in AS than LN, and were significantly higher in Akita than in Miyagi.

\subsection{Effect on the Growth and N Uptake of Rice Plants}

Changes in the plant height, the number of tillers and the leaf color value (also known as the SPAD value) with time are shown in Figure 4. No significant differences in those parameters with fertilizer at any measurement time were found. Significant differences in the plant height were not observed with fertilizer throughout the growing season. The number of tillers with fertilizer in Akita showed a similar trend throughout the growing season, and the number of panicles at the full heading stage with fertilizer also was not significantly different. Although the number of tillers in Miyagi was higher in the AS than in the LN at the tillering stage, the number of tillers at the maximum tiller number stage and the number of panicles at the full heading stage with fertilizer were similar. The SPAD value in Akita was higher for LN than AS at the maximum tiller number and panicle initiation stages with fertilizer and similar at the full heading stage. The SPAD value in Miyagi was higher for LN than AS at the tillering stage and did not differ with fertilizer. 


\begin{tabular}{|c|c|c|c|c|c|c|c|c|}
\hline \multirow[b]{2}{*}{ Timing } & \multirow[b]{2}{*}{ Factor } & \multicolumn{5}{|c|}{ Components } & \multicolumn{2}{|l|}{ Sum } \\
\hline & & Plant & Rice straw & $\begin{array}{l}\text { Labile } \\
\text { soil N }\end{array}$ & $\begin{array}{c}\text { Recalcitrant } \\
\text { soil N }\end{array}$ & Loss & $\begin{array}{c}\text { Soil } \\
\text { (Labile + Recalcitrant) }\end{array}$ & $\begin{array}{c}\text { Rice straw } \\
+ \text { Soil }\end{array}$ \\
\hline \multirow{3}{*}{$\begin{array}{c}\text { Before } \\
\text { cultivation }\end{array}$} & Fertilizer & - & ns $(P=0.083)$ & ns & * & * & ns $(P=0.059)$ & * \\
\hline & Site & - & *** & ** & *** & *** & $* *$ & *** \\
\hline & $F * S$ & - & ns & ns & ns & ns & ns & ns \\
\hline \multirow{3}{*}{ Harvesting } & Fertilizer & *** & - & $*$ & *** & $*$ & *** & - \\
\hline & Site & *** & - & *** & * & *** & $* *$ & - \\
\hline & $F^{*} S$ & ns & - & ns & $*$ & ** & *** & - \\
\hline
\end{tabular}

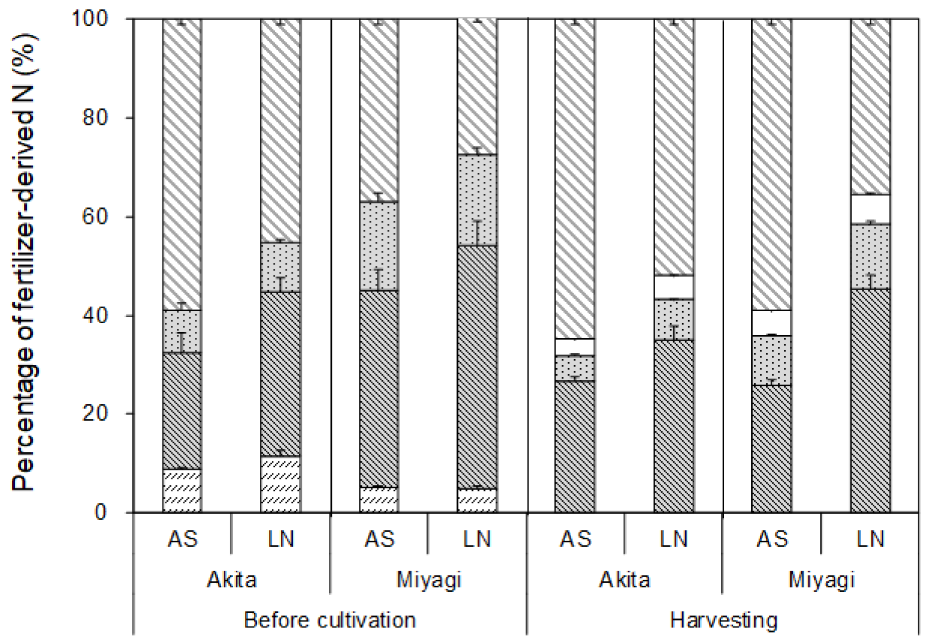

Figure 3. Distribution of fertilizer-derived $\mathrm{N}$ before cultivation and at the harvesting stage. AS, ammonium sulfate; $\mathrm{LN}$, lime nitrogen. The error bars show the standard error $(n=4)$.
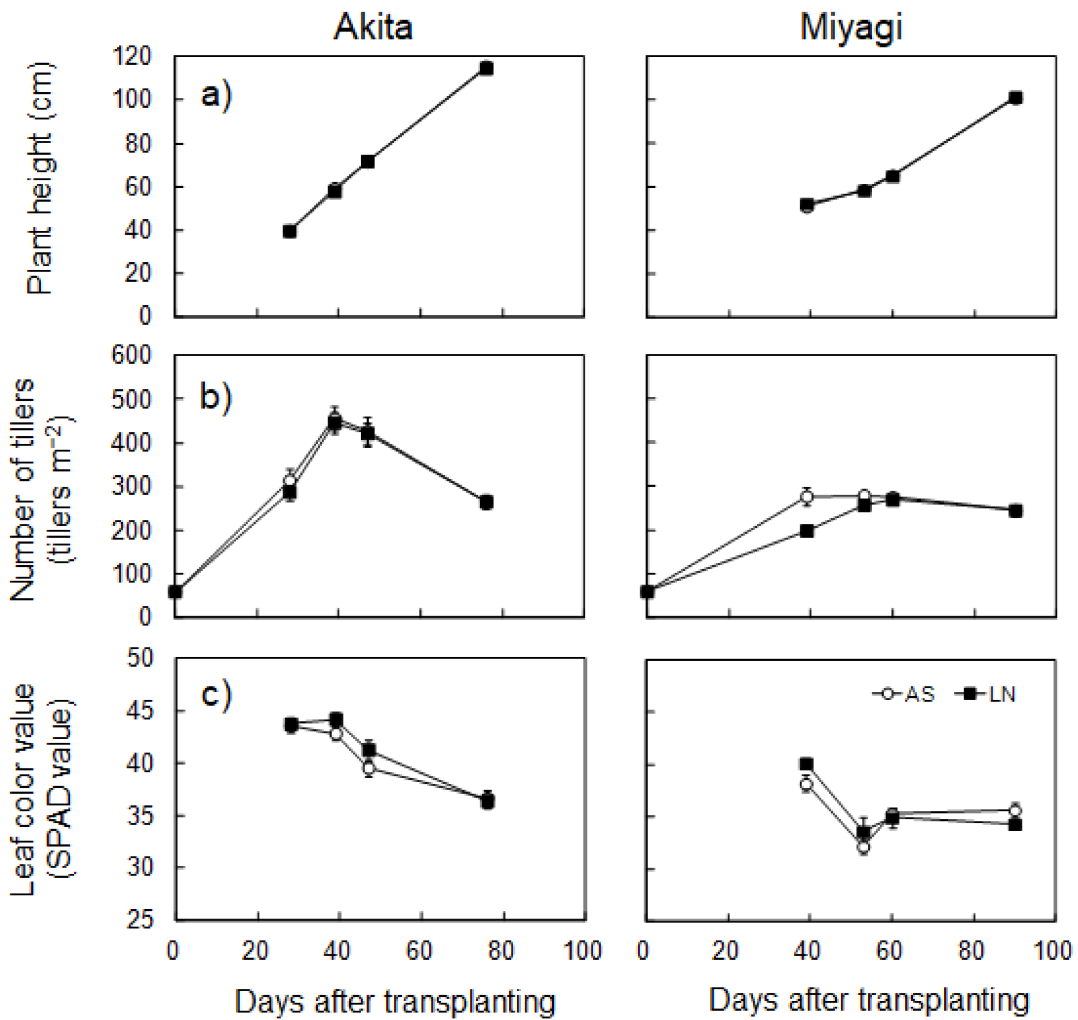

Figure 4. Changes in plant height (a); number of tillers (b) and the leaf color value (SPAD value; (c)). Each measurement corresponds to the following order: tillering, maximum tiller number, panicle initiation and full heading stages, respectively. The error bars show the standard error $(n=8$, except for $n=4$ in the full heading stage). There were no significant differences with fertilizer for all measurements $(p>0.05, t$-test). 
The aboveground dry matter weights of the rice plants at the panicle initiation and harvesting stages are shown in Table 3 . The aboveground dry matter weights did not significantly differ with fertilizer at either site or at any stage. The plant uptake of the total $\mathrm{N}$ and fertilizer-derived $\mathrm{N}$ during each growing period are shown in Table 4. Similar to the dry matter weight, the amount of total plant $\mathrm{N}$ uptake did not significantly differ with fertilizer at any period at either site. The plant uptake of fertilizer-derived $\mathrm{N}$ during the early growing season (from transplanting to the panicle initiation stage) was higher for LN (0.14-0.20 $\left.\mathrm{g} \mathrm{N} \mathrm{m}^{-2}\right)$ than AS $\left(0.09-0.18 \mathrm{~g} \mathrm{~N} \mathrm{~m}^{-2}\right)$, and this difference was significant in Akita. Additionally, the plant uptake of fertilizer-derived $\mathrm{N}$ during the late growing season (from the panicle initiation stage to the harvesting stage) was almost the same $\left(0.05-0.07 \mathrm{~g} \mathrm{~N} \mathrm{~m}^{-2}\right)$, regardless of the site and fertilizer and was lower than during the early growing season. The plant uptake of fertilizer-derived $\mathrm{N}$ at the harvesting stage was significantly higher for $\mathrm{LN}\left(0.21-0.27 \mathrm{~g} \mathrm{~N} \mathrm{~m}^{-2}\right)$ than AS $\left(0.15-0.22 \mathrm{~g} \mathrm{~N} \mathrm{~m}^{-2}\right)$.

Table 3. Aboveground dry matter weight at the panicle initiation and harvesting stages $\left(\mathrm{g} \mathrm{m}^{-2}\right)$.

\begin{tabular}{ccccc}
\hline \multirow{2}{*}{ Fertilizer } & \multicolumn{2}{c}{ Panicle Initiation Stage } & \multicolumn{2}{c}{ Harvesting Stage } \\
\cline { 2 - 5 } & Akita & Miyagi & Akita & Miyagi \\
\hline AS & $293 \pm 27$ & $385 \pm 21$ & $931 \pm 54$ & $858 \pm 57$ \\
LN & $289 \pm 61$ & $413 \pm 31$ & $960 \pm 11$ & $864 \pm 12$ \\
-test $^{+}$ & ns & ns & ns & ns
\end{tabular}

Values represent the mean \pm standard error $(n=4) .{ }^{+}$By $t$-test, ns for $p>0.05 ;{ }^{*}$ for $p<0.05 ;{ }^{* *}$ for $p<0.01$. AS, ammonium sulfate; LN, lime nitrogen.

Table 4. Plant uptake of total and fertilizer-derived $\mathrm{N}$ during each growing period.

\begin{tabular}{|c|c|c|c|c|c|c|}
\hline \multirow{3}{*}{ Fertilizer } & \multicolumn{6}{|c|}{ Total N Uptake $\left(\mathrm{g} \mathrm{N} \mathrm{m}^{-2}\right)$} \\
\hline & \multicolumn{2}{|c|}{ TP to PI(at PI) } & \multicolumn{2}{|c|}{ PI to $\mathrm{H}(\mathrm{H}-\mathrm{PI})$} & \multicolumn{2}{|c|}{ Total(at H) } \\
\hline & Akita & Miyagi & Akita & Miyagi & Akita & Miyagi \\
\hline AS & $4.78 \pm 0.11$ & $4.96 \pm 0.16$ & $3.48 \pm 0.27$ & $2.03 \pm 0.24$ & $8.26 \pm 0.30$ & $7.19 \pm 0.38$ \\
\hline LN & $4.93 \pm 0.31$ & $4.97 \pm 0.21$ & $3.35 \pm 0.40$ & $1.61 \pm 0.36$ & $8.29 \pm 0.25$ & $6.53 \pm 0.26$ \\
\hline$t$-test ${ }^{\dagger}$ & ns & ns & ns & ns & ns & ns \\
\hline \multirow{3}{*}{ Fertilizer } & \multicolumn{6}{|c|}{ Fertilizer-Derived $\mathrm{N}$ Uptake $\left(\mathrm{g} \mathrm{N} \mathrm{m}^{-2}\right.$ ) } \\
\hline & \multicolumn{2}{|c|}{ TP to PI(at PI) } & \multicolumn{2}{|c|}{ PI to $\mathrm{H}(\mathrm{H}-\mathrm{PI})$} & \multicolumn{2}{|c|}{ Total(at H) } \\
\hline & Akita & Miyagi & Akita & Miyagi & Akita & Miyagi \\
\hline AS & $0.09 \pm 0.01$ & $0.18 \pm 0.01$ & $0.05 \pm 0.01$ & $0.05 \pm 0.01$ & $0.15 \pm 0.01$ & $0.22 \pm 0.01$ \\
\hline LN & $0.14 \pm 0.01$ & $0.20 \pm 0.01$ & $0.07 \pm 0.01$ & $0.06 \pm 0.01$ & $0.21 \pm 0.01$ & $0.27 \pm 0.00$ \\
\hline$t$-test ${ }^{\dagger}$ & $* *$ & ns & ns & ns & $* *$ & $* *$ \\
\hline
\end{tabular}

Values represent the mean \pm standard error $(n=4) .{ }^{\dagger}$ By $t$-test, ns for $p>0.05 ;{ }^{*}$ for $p<0.05 ;{ }^{* *}$ for $p<0.01$. $\mathrm{H}$, harvesting stage; PI, panicle initiation stage; TP, transplanting. AS, ammonium sulfate; LN, lime nitrogen.

\subsection{Dynamics of Fertilizer-Derived N during Rice Growing Season}

The distribution of fertilizer-derived $\mathrm{N}$ at the harvesting stage is shown in Figure 3. The percentages of plant $\mathrm{N}$ derived from LN (4.9-6.2\%) were significantly higher than those from AS (3.4-5.3\%). Similarly, the percentages of soil $\mathrm{N}$ derived from LN (42-61\%) were significantly higher than those from AS (31-38\%). The percentages of both labile and recalcitrant soil N derived from LN (8.1-13.2\% and $35-45 \%$, respectively) were also significantly higher than those from AS (5.1-9.8\% and $26-27 \%$, respectively). The percentage of labile soil fertilizer-derived $\mathrm{N}$ decreased compared with that before cultivation, and this decrement was higher in Miyagi compared with that in Akita. The percentage of recalcitrant soil fertilizer-derived $\mathrm{N}$ slightly increased or decreased compared with the value before cultivation, except for a drastic decrease of AS in Miyagi (40-26\%). The proportion of labile soil N 
derived from fertilizer to the total fertilizer-derived $\mathrm{N}$ in the soil was $16-27 \%$, and the percentage decreased from that before cultivation.

The percentages of $\mathrm{N}$ in plant and soil (including labile and recalcitrant) from fertilizer in Miyagi were significantly higher than those in Akita. Losses of $\mathrm{N}$ derived from fertilizer ranged from 35 to $65 \%$, and were significantly higher in AS than LN, and were significantly higher in Akita than in Miyagi. Interaction between fertilizer and site were found in recalcitrant soil N, soil N and loss of N. Based on the test of the simple main effect, the effect of the site at AS was not significant. The interactions could be mainly caused by the drastic decrease of recalcitrant soil $\mathrm{N}$ derived from AS in Miyagi during the cultivation period.

\section{Discussion}

\subsection{Rice Straw Decomposition}

No significant effect of fertilizer (AS or LN) on rice straw decomposition was found (Figure 2). A field experiment in Hokkaido in northern Japan, reported that the decomposition rate of rice straw incorporated into the soil in autumn (from the incorporation to the cultivation in the next spring on a $C$ basis) was significantly higher with fertilizer application of 3-4 $\mathrm{g} \mathrm{N} \mathrm{m}^{-2}(41-51 \%)$ than with no application (35-44\%) [16]. The decomposition rates were also reported for Niigata (43-46\% on a C basis, [2]) and Miyagi (35\% on a dry-matter basis, [17]), both located in northern Japan. Although the method for evaluating the decomposition rate was different from that in the previous reports (burying the rice straw wrapped with a net or unwoven cloth in the soil), the decomposition rates in this study (49-57\%) were comparable or relatively higher. Consequently, rice straw decomposition in this study agreed generally with previous reports in this region.

The $\mathrm{C} / \mathrm{N}$ ratios in Akita were lower than those in Miyagi (Figure 2), and the tendency was opposite from that of their initial value. This might be caused by higher soil $\mathrm{N}$ availability in Akita (Table 2).

\subsection{Dynamics of Fertilizer $N$ and its Effect on Plant Growth}

During the fallow season, the amount of fertilizer-derived $\mathrm{N}$ in the soil (plowed layer) that was applied to enhance rice straw decomposition in autumn decreased by $28-59 \%$ (Figures 3 and 5). The percentage of fertilizer-derived $\mathrm{N}$ in the soil + rice straw was higher in LN than in AS. This difference could reflect different characteristics of the $\mathrm{N}$ release process from each fertilizer. AS is a quick-acting fertilizer that rapidly releases $\mathrm{NH}_{4}-\mathrm{N}$ after incorporation into the soil. A portion of the released $\mathrm{NH}_{4}-\mathrm{N}$ in the soil is oxidized to $\mathrm{NO}_{3}-\mathrm{N}$ by nitrification. The $\mathrm{NO}_{3}-\mathrm{N}$ is easily lost from the plowed layer soil by leaching via percolation and denitrification. However, LN, a kind of controlled-release fertilizer, inhibits nitrification of the released $\mathrm{N}$ by cyanamide and dicyandiamide, which are the degradation products of this fertilizer. Due to this nitrification inhibitory effect, $\mathrm{N}$ derived from $\mathrm{LN}$ could remain in the soil as $\mathrm{NH}_{4}-\mathrm{N}$ longer than $\mathrm{N}$ derived from AS [5,6]. Consequently, more $\mathrm{N}$ derived from $\mathrm{LN}$ remained in the soil than from AS, with less $\mathrm{N}$ losses. Before cultivation, the proportion of labile soil $\mathrm{N}$ derived from fertilizer to the total fertilizer-derived $\mathrm{N}$ in the soil were similar for the two fertilizers and the sites (23-31\%, Figure 3), suggesting a minor effect of fertilizer type on the residual form of fertilizer-derived $\mathrm{N}$ in the soil.

The percentage of plant $\mathrm{N}$ derived from $\mathrm{LN}$ at the harvesting stage was significantly higher than from AS, likely reflecting the differences in the $\mathrm{N}$ remaining in the soil and rice straw before cultivation (Figure 3). Approximately 30-50\% of labile soil $\mathrm{N}$ derived from fertilizer before cultivation was taken up by the plants at the harvesting stage. Specifically, fertilizer-derived $\mathrm{N}$ uptake was higher during the early growing season than during the late growing season, and the differences in fertilizer-derived $\mathrm{N}$ uptake with fertilizer (AS $<\mathrm{LN}$ ) were significant only during the early growing season in Akita (Table 4). These results suggest that less $\mathrm{N}$ derived from LN was lost during the fallow season than from AS and could be efficiently utilized by the rice plants in the following early growing season. 


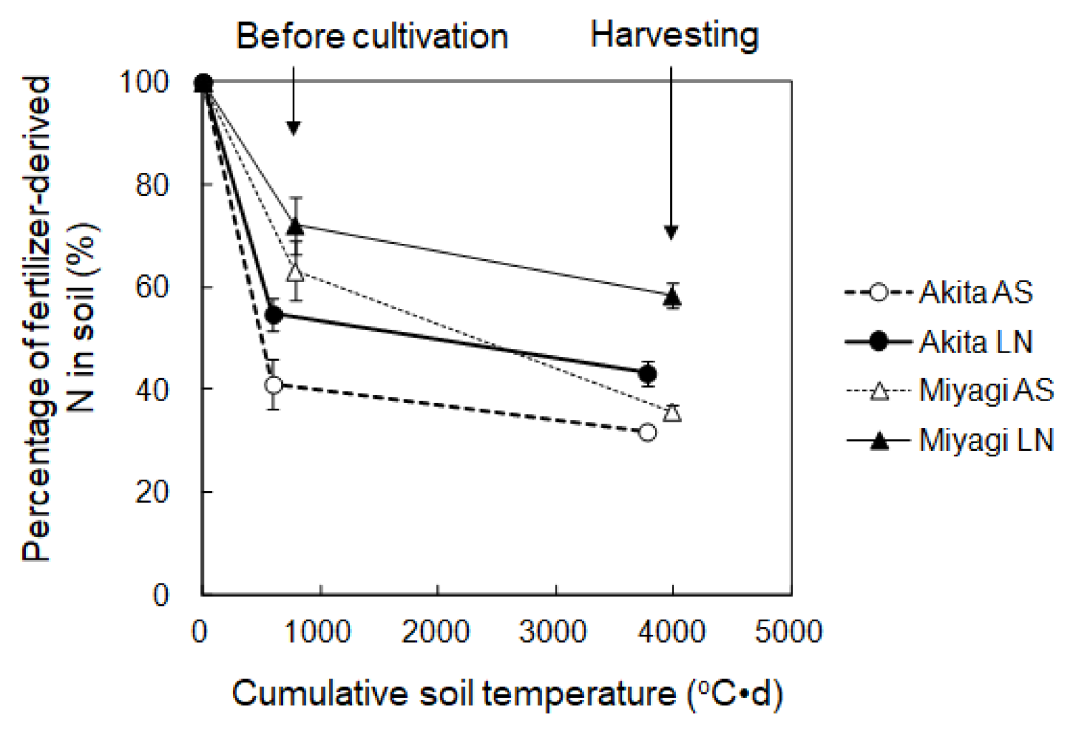

Figure 5. Temporal changes in percentage of fertilizer-derived $\mathrm{N}$ in the soil. AS, ammonium sulfate; $\mathrm{LN}$, lime nitrogen. The values determined "Before cultivation" involved the percentage of $\mathrm{N}$ in the rice straw. The error bars show the standard error $(n=4)$.

Takahashi et al. [10] suggested the amount of basal fertilizer should be reduced when rice straw is treated with $4 \mathrm{~g} \mathrm{~N} \mathrm{~m}^{-2}$ of $\mathrm{LN}$ in autumn to avoid an excessive luxuriant growth of the rice crop (cultivar: Sasanishiki) in the next year based on a field cultivation experiment in Miyagi prefecture. The plant uptake of $\mathrm{N}$ derived from AS and LN was $0.15-0.22$ and $0.21-0.27 \mathrm{~g} \mathrm{~N} \mathrm{~m}^{-2}$, respectively. Assuming that the recovery rate of basal $\mathrm{N}$ fertilizer by broadcast application was $30 \%$, the amount was comparable to the $\mathrm{N}$ uptake derived from basal fertilizer, with an application rate of $0.5-0.7$ and $0.7-0.9 \mathrm{~g} \mathrm{~N} \mathrm{~m}^{-2}$, respectively, in this study. Therefore, when $4 \mathrm{~g} \mathrm{~N} \mathrm{~m}^{-2}$ of $\mathrm{LN}$ was applied in autumn [1,10,16], a reduction of $1 \mathrm{~g} \mathrm{~N} \mathrm{~m}^{-2}$ in the basal fertilizer application rate was appropriate, considering the plant uptake of the applied $\mathrm{N}$.

At the harvesting stage, although the plant uptake of the $\mathrm{N}$ derived from $\mathrm{LN}$ was higher than from AS, the fertilizer-derived $\mathrm{N}$ accounted for only 3-6\% of the plant uptake of the total $\mathrm{N}$ (Table 4). Therefore, the differences in the fertilizer-derived $\mathrm{N}$ uptake did not significantly affect rice plant growth, specifically plant height, number of tillers and dry matter weight, during the next year (Figure 4, Tables 3 and 4).

The percentage of $\mathrm{N}$ derived from $\mathrm{LN}$ in the soil at the harvesting stage was significantly higher than from AS as well as the percentage in plants (Figure 3), reflecting differences in the $\mathrm{N}$ remaining in the rice straw + soil before cultivation. The decrease in the percentage of fertilizer-derived $\mathrm{N}$ in the soil (including rice straw) during the growing period ranged from $10 \%$ to $12 \%$, except for AS in Miyagi $(22 \%)$, and was lower than the loss during the fallow season (28-59\%). Additionally, the differences in the rate of decrease were similar between sites and fertilizers (Figure 5). Therefore, losses of fertilizer-derived $\mathrm{N}$ applied in autumn primarily occurred during the fallow season, and most of the $\mathrm{N}$ remaining in the soil was considered to be relatively stable organic $\mathrm{N}$ before cultivation. Thereafter, a portion of the organic $\mathrm{N}$ could be mineralized and taken up by the rice plants during the following growing season. Although the significant decrease in soil N derived from AS in Miyagi during the growing period primarily reflected a decrease in recalcitrant soil N (Figure 3), the reason for that considerable decrease remained elusive.

At harvesting, the percentages of $\mathrm{N}$ in plant and soil (including labile and recalcitrant) derived from LN were significantly higher than those from AS in both Akita and Miyagi with different climates (Figure 3). This implies that the results of this study could be applied throughout northern Japan. 
Before cultivation, the percentages of the remaining fertilizer-derived $\mathrm{N}$ in the rice straw + soil were significantly higher in Miyagi than Akita (Figure 3). Precipitation in October and November after the fertilizer application was lower in Miyagi $(169 \mathrm{~mm})$ than in Akita $(302 \mathrm{~mm})$ (Figure 1). It is likely that the loss of fertilizer-derived $\mathrm{N}$ to the outside of the plowed layer soil via leaching in Miyagi was lower than that in Akita. Consequently, the application of fertilizer $\mathrm{N}$ for enhancing rice straw decomposition could contribute to the maintenance of soil $\mathrm{N}$ fertility, and this effect might be higher in regions with low precipitation after application in autumn. To confirm the implication, further studies with replications at site level are required.

\subsection{Further Implications}

The percentage of plant uptake of fertilizer-derived $\mathrm{N}$ was $3.4-6.2 \%$. These values were lower than the recovery rate of LN applied to rice as a basal dressing (9.1-17\%) according to Ohsumi et al. [18], suggesting that the rate associated with application in autumn is lower than that with application prior to transplanting. However, at the harvesting stage, 31-61\% $\left(1.7-2.5 \mathrm{~g} \mathrm{~N} \mathrm{~m}^{-2}\right)$ of the fertilizer-derived $\mathrm{N}$ remained in the soil; specifically, $5.1-13.2 \%\left(0.22-0.57 \mathrm{~g} \mathrm{~N} \mathrm{~m}^{-2}\right)$ existed as labile soil $\mathrm{N}$ (Figure 3), suggesting that a portion of the fertilizer-derived $\mathrm{N}$ could be taken up by the rice plants in the following year. Consequently, although no significant effect of fertilizer-derived $\mathrm{N}$ applied to enhance rice straw decomposition on the growth of rice plants in a single year was noted, the trend suggested that the $\mathrm{N}$ largely remained in the soil, which could contribute to the maintenance of soil $\mathrm{N}$ fertility. The effect on the soil $\mathrm{N}$ fertility was higher for $\mathrm{LN}$, which had a high percentage of $\mathrm{N}$ remaining in the soil. Additionally, continuous application of fertilizer to enhance rice straw decomposition in a paddy field could lead to the accumulation of fertilizer-derived $\mathrm{N}$ in the soil. Since the accumulated $\mathrm{N}$ could increase the amount of $\mathrm{N}$ taken up by the rice plants and affect their growth, future research about the fate of continuously applied fertilizer-derived $\mathrm{N}$ is necessary.

Previous studies related to the enhancement of rice straw decomposition were conducted with fertilizer application and rice straw incorporation in autumn $[1,10]$. However, in a paddy field in cool-temperate and snowy regions, the rice straw incorporation in autumn is sometimes difficult due to the short time for agricultural activity and the risk for the degradation of field conditions in the following spring. Although this study was also conducted with the application and incorporation in autumn, the fate of $\mathrm{N}$ derived from the fertilizer incorporated in the spring could be different to that in autumn. Thus, future research involving an evaluation of the fate of fertilizer-derived $\mathrm{N}$ applied in autumn and incorporated in the spring is necessary.

Recently, the cultivation of non-staple food rice, such as forage rice, as an alternative crop in paddies has increased considerably [19]. The use of high-yielding varieties is essential for the cultivation of non-staple food rice, reflecting the low cost of production compared with staple food rice production. In whole-crop silage production, both unhulled rice and rice straw are utilized. While, in non-staple food rice cultivation, only unhulled rice is harvested with a combine, so the amount of rice straw left in the paddy field increases with an increase in the rice yield [20]. A higher amount of rice straw in the paddy field could enhance the reduction of saturated soil and inhibit the early growth of rice during next year's rice-growing season [20] and could increase methane emissions from the rice paddy field, which is a major greenhouse gas [21,22]. Therefore, the management of rice straw after the harvest could become even more important for the cultivation of non-staple food rice. The enhancement of rice straw decomposition by the application of LN in autumn enhances rice growth [1] and suppresses methane emissions from a paddy field [23], suggesting that this practice is promising for rice straw management for high-yielding cultivation.

\section{Conclusions}

In two paddy fields at different locations in a cool-temperate climate, rice plant uptake of $\mathrm{N}$ derived from LN applied to enhance rice straw decomposition in the previous autumn were higher than those from AS, although there were no significant differences in the growth of rice plants between them. 
Moreover, fertilizer-derived $\mathrm{N}$ in soil after one year of rice cultivation was also significantly higher for $\mathrm{LN}$ than for AS. Consequently, the application of $\mathrm{N}$ fertilizer to enhance rice straw decomposition could contribute to the maintenance of soil $\mathrm{N}$ fertility, and this effect was higher for LN compared with AS.

Supplementary Materials: The following are available online at http:/ /www.mdpi.com/2077-0472/8/4/50/s1, Table S1: Distribution of fertilizer-derived N before cultivation and at the harvesting stage.

Acknowledgments: The authors would like to thank the staff members of the Center of Field Education and the Research, Faculty of Bioresource Sciences, Akita Prefectural University, and the School of Food, Agricultural and Environmental Sciences at Miyagi University for support with the management of the experimental field. The authors would also like to thank Mitsuo Saito (Miyagi University) for support throughout the experiment and the Japan Lime Nitrogen Industries Association for providing the ${ }^{15} \mathrm{~N}$-labeled fertilizers.

Author Contributions: Kazuhiko Kimura and Yoshihiro Kaneta conceived and designed the experiments; Fumiaki Takakai, Seiya Hirano, Yuka Harakawa and Keiko Hatakeyama performed the experiments and analyzed the data; Kentaro Yasuda contributed cultivation and measurements in the experimental field; Fumiaki Takakai wrote the paper; Takashi Sato and Yoshihiro Kaneta gave many constructive comments on this manuscript.

Conflicts of Interest: The authors declare no conflict of interest.

\section{References}

1. Chiba, M.; Shimazu, R.; Muto, K.; Uchida, S. Stable yield of the paddy rice by rice straw plowing. Bull. Iwate Agric. Exp. Stn. 1980, 22, 81-117. (In Japanese)

2. Kubota, M. Reasonable application of rice straw to wet and semiwet paddy fields with heavy clay soil in Niigata. J. Niigata Agric. Exp. Stn. 1992, 39, 1-87. (In Japanese)

3. Japan Lime Nitrogen Industries Association. Technical Information Q\&A. 2012. Available online: http: / / www.cacn.jp/technology / qa.html (accessed on 29 March 2018). (In Japanese)

4. Owa, N.; Hiradate, S.; Fujii, Y. Analysis of inhibition effect of nitrification by cyanamide, the main component of lime nitrogen (Sekkaichisso no shuseibun shianamido no shousankaseiyokuseisayou no kaiseki). Soil Microorg. 2010, 64, 137. (In Japanese)

5. Kaneta, Y.; Goto, S.; Sato, T.; Takakai, F.; Yasuda, K.; Nosaka, T.; Sakashita, Y.; Urano, Y.; Ohyama, T. Effect of deep placement of calcium cyanamide on winter wheat in a heavy clay upland field formerly used to grow paddy rice. Jpn. J. Soil Sci. Plant Nutr. 2014, 85, 446-452. (In Japanese)

6. Yamamoto, A.; Akiyama, H.; Naokawa, T.; Yagi, K. Effect of lime-nitrogen application on $\mathrm{N}_{2} \mathrm{O}$ emission from an Andosol vegetable field. Soil Sci. Plant Nutr. 2012, 58, 245-254. [CrossRef]

7. Hirono, Y.; Nonaka, K. Effects of application of lime nitrogen and dicyandiamide on nitrous oxide emissions from green tea fields. Soil Sci. Plant Nutr. 2014, 60, 276-285. [CrossRef]

8. Yamamoto, A.; Akiyama, H.; Naokawa, T.; Yagi, K. Lime-nitrogen application reduces $\mathrm{N}_{2} \mathrm{O}$ emission from a vegetable field with imperfectly-drained sandy clay-loam soil. Soil Sci. Plant Nutr. 2013, 59, 442-449. [CrossRef]

9. Yamamoto, A.; Akiyama, H.; Naokawa, T.; Miyazaki, Y.; Honda, Y.; Sano, Y.; Nakajima, Y.; Yagi, K. Lime-nitrogen application affects nitrification, denitrification, and $\mathrm{N}_{2} \mathrm{O}$ emission in an acidic tea soil. Biol. Fertil. Soils 2014, 50, 53-62. [CrossRef]

10. Takahashi, H.; Kato, M.; Kitazawa, A.; Shiojima, M.; Aasano, I.; Saito, M. Effects of continuous application of plown-in rice straw and incinerated rice straw to fine-textured strong gley soils on rice yield and paddy soil. Bull. Miyagi Prefect. Furukawa Agric. Exp. Stn. 2010, 8, 23-34. (In Japanese)

11. Nishida, M.; Sumida, H.; Kato, N. Fate of nitrogen derived from ${ }^{15} \mathrm{~N}$-labeled cattle manure compost applied to a paddy field in the cool climate region of Japan. Soil Sci. Plant Nutr. 2008, 54, 459-466. [CrossRef]

12. Cultivated Soil Classification Committee. Classification of cultivated soils in Japan: Third approximation. Misc. Publ. Natl. Inst. Agro-Environ. Sci. 1995, 17, 1-79. (In Japanese)

13. Food and Agriculture Organization of the United Nations (FAO). World Reference Base for Soil Resources; FAO: Rome, Italy, 2006.

14. Ogawa, Y.V. 10 Available nitrogen. In Methods for Soil Environment Analysis; Konno, T., Ed.; Hakuyusha: Tokyo, Japan, 1997; pp. 255-262. (In Japanese) 
15. Yoneyama, T.; Arima, Y.; Kumazawa, K. Sample preparation from dilute ammonium Solution for emission spectrographic analysis of heavy nitrogen. Jpn. J. Soil Sci. Plant Nutr. 1975, 46, 146-147. (In Japanese)

16. Goto, E.; Miyamori, Y.; Hasegawa, S.; Inatsu, O. Reduction effects of accelerating rice straw decomposition and water management on methane emission from paddy fields in a cold distinct. Jpn. J. Soil Sci. Plant Nutr. 2004, 75, 191-201. (In Japanese)

17. Saigusa, M.; Hanaki, M.; Ito, T. Decomposition pattern of rice straw in poorly drained paddy soil and recovery rate of straw nitrogen by rice plant in no-tillage transplanting cultivation. Jpn. J. Soil Sci. Plant Nutr. 1999, 70, 157-163. (In Japanese)

18. Ohsumi, A.; Heinai, H.; Matsumura, O. Yield and appearance quality of rice cultivated with basal dressing with lime nitrogen on clayey gley soil. Jpn. J. Crop Sci. 2013, 82, 28-33. (In Japanese) [CrossRef]

19. Ministry of Agriculture. Forestry and Fisheries. 2017. Available online: http://www.e-stat.go.jp/SG1/estat/ Pdfdl.do?sinfid=000031591756 (accessed on 29 March 2018). (In Japanese)

20. Kobayashi, A.; Suzuki, Y.; Saiten, H.; Morooka, M.; Ishida, H. Effects of early release of ponding water on growth and yield of wetland rice under heavy application if rice straw in clayey gley paddy soil. Bull. Hokuriku Agric. Exp. Stn. 2000, 43, 25-45. (In Japanese)

21. Naser, H.M.; Nagata, O.; Tamura, S.; Hatano, R. Methane emissions from five paddy fields with different amounts of rice straw application in central Hokkaido, Japan. Soil Sci. Plant Nutr. 2007, 53, 95-101. [CrossRef]

22. Watanabe, A.; Satoh, Y.; Kimura, M. Estimation of the increase in $\mathrm{CH}_{4}$ emission from paddy soils by rice straw application. Plant Soil 1995, 173, 225-231. [CrossRef]

23. Miura, Y. Rice straw management for mitigation of methane emission from paddy field. Spec. Bull. Fukushima Prefect. Agric. Exp. Stn. 2003, 7, 1-38. (In Japanese)

(C) 2018 by the authors. Licensee MDPI, Basel, Switzerland. This article is an open access article distributed under the terms and conditions of the Creative Commons Attribution (CC BY) license (http:/ / creativecommons.org/licenses/by/4.0/). 